\title{
Utilizing GRACE and GLDAS data for estimating groundwater storage variability over the Krishna Basin
}

\author{
Akhilesh S. Nair ${ }^{1}$, J. Indu ${ }^{1,2}$ * \\ ${ }^{1}$ Department of Civil Engineering, Indian Institute of Technology Bombay, Mumbai, India- akhileshn@iitb.ac.in \\ ${ }^{2}$ Interdisciplinary Centre for Climate Studies, Indian Institute of Technology Bombay, Mumbai, India - indusj@civil.iitb.ac.in
}

Commission V, SS: Disaster Monitoring, Damage Assessment, and Risk Reduction

KEYWORDS: GRACE, Mascon, groundwater, precipitation, entropy, evapotranspiration

\begin{abstract}
:
Groundwater is utilized intensively as a source of fresh water for irrigation and human needs. Hence, it is necessary to monitor groundwater storage for water security of the region in the future. The present study aims to evaluate the groundwater resource over the Krishna basin in South India. The basin comprises of 210 major and medium irrigation projects, which makes it important to evaluate the groundwater balance for a sustainable groundwater draft. This study evaluates the trend in groundwater anomaly derived from GRACE mascon product. Results indicate that the Krishna basin is subjected to a strong decline in groundwater at a rate of 0.34 $\mathrm{cm}$ per year. Further, the study explores the seasonality of precipitation and its effect on groundwater by adopting an entropy-based approach. Results indicate the combined effect of delay in precipitation to attain peak and reduced duration of the wet season as a primary reason for the decline in the groundwater storage. The result shows that the reduction in groundwater storage affects the evapotranspiration over the region.
\end{abstract}

\section{INTRODUCTION}

Groundwater is the major continuous source of freshwater in many parts of the world. Particularly in India, $85 \%$ of the total annual groundwater draft is utilized for agriculture (FAO 2012). The groundwater storage is depleting at an alarming rate owing to its overexploitation for irrigation. As mentioned in IWRS 1997 the haphazard use of groundwater can lead to severe waterdeficit, particularly over all of northwestern India, the southern plateau and southeastern coastal region by year 2025 . Rodell et al., 2009 indicated a depletion of groundwater at a mean rate of $4.0 \pm 1.0 \mathrm{~cm}$ per year across the states of Rajasthan, Punjab, Haryana, and western Uttar Pradesh. The increasing groundwater demand for irrigation poses a critical question about the future feasible of groundwater draft from the basin and water security of this region. Therefore, assessment and sustainable management of water balance are critical due to the dependence of the high population density and intensive agriculture activities on groundwater storage.

The sparse distribution of in situ hydrometeorological stations poses a major challenge to evaluate the variability of groundwater resources. The model simulations are also subjected to error owing to hilly topographic terrains (Nair and Indu, 2017; Nair and Indu, 2018). The central groundwater board (CGWB) of India provides observations from more than 30,000 monitoring wells for four seasons. These observations lack information about deep aquifers as they pertain to shallow aquifer depths. The recent development in spaceborne remote sensing has provided a myriad of land surface observations. Some of the operational satellites providing surface soil moisture include the Meteorological Operational (METOP) satellites (Wagner et al., 2013), Coriolis satellite (Gaiser et al., 2004), the Global Change Observation Mission-Water (GCOM-W) satellite, Soil Moisture Ocean Salinity (SMOS) mission (Kerr et al., 2010) and the Soil
Moisture Active Passive (SMAP) mission (Entekhabi et al., 2010). In addition to this, satellites are equipped with an advanced radar altimeter, which has the ability to monitor water levels over lakes, rivers, and floodplains. The Gravity Recovery and Climate Experiment (GRACE) mission provide observations of terrestrial water storage (TWS) changes from 2002. The GRACE TWS anomaly includes the vertical integration of water balance components such as surface water, soil moisture, snow, and groundwater. GRACE observations are particularly useful in areas with scarce networks of ground-based observations (Swenson and Wahr, 2009).

The principal objective of GRACE mission is to monitor the total terrestrial mass fluctuation with the variation in gravity field from satellite gravimetric measurements. Studies have efficiently used GRACE observations to monitor the groundwater variability at regional and global scales (Hassan and Jin, 2014). In a study by Swenson and Wahr, 2009, the GRACE observations could successfully capture the water level variations in Lake Victoria caused due to drought and human activities. Becker et al., 2010 utilized the GRACE data to explore the variability in TWS and lake water volume over each Africa and found that Indian Ocean Dipole (IOD) was a major factor in the variation in total water discharge. Similarly, different studies have utilized GRACE observations to monitor groundwater depletion over India (Rodell et al., 2009; Tiwari et al., 2009, Chen et. al., 2014), the recent studies on this topic are from Bhanja et al., 2016; Asoka et al., 2017, Banerjee and Kumar, 2018. However, the majority of this studies are focused on the northwest India aquifers (Indo Gangetic Basins) neglecting the southern regions. Furthermore, they have evaluated GRACE observations for a period from 2002 to 2013 or before. Considering all these points the present study utilizes GRACE TWS observations to evaluate the groundwater variability over the Krishna basin in the south Indian peninsula for a period from 2002 to 2016 .

\footnotetext{
* Corresponding author
} 


\section{STUDY AREA AND DATA USED}

\subsection{Study Area}

The present study is performed on the Krishna Basin (Fig. 1). It covers nearly $8 \%(2,58,948 \mathrm{Sq} . \mathrm{Km})$ of the total geographical area of India, extending over states of Maharashtra, Karnataka and Andhra Pradesh. It lies between $73^{\circ} 17^{\prime}$ to $81^{\circ} 9^{\prime}$ east and $13^{\circ} 17^{\prime}$ to $19^{0} 22^{\prime}$ north with a length of $701 \mathrm{~km}$ and width of 672 $\mathrm{km}$. This basin is surrounded by Balaghat range on the north, the Eastern Ghats in the east and the Western Ghats in the west. It receives an average annual rainfall of $784 \mathrm{~mm}$ during the southwest monsoon season from June, July, August, and September (JJAS). The basin is covered with agricultural land accounting for $75.86 \%$ of the total area (Fig. 1b) (National Institute of Hydrology). It has 210 major and medium irrigation projects in completed and ongoing stages (Major irrigation projects: Completed- 32, ongoing- 41; Medium Irrigation projects: Completed - 104, ongoing-30, proposed-3) (India-WRIS WebGIS). Therefore, it is very crucial to evaluate the groundwater storage over the Krishna basin for future feasibility and sustainability of groundwater draft

\subsection{GRACE observations}

For the present study groundwater storage variability over the Krishna basin is evaluated using GRACE observations. The change in terrestrial water storage can be derived from GRACE monthly gravity anomalies (Rodell and Famiglietti,1999). GRACE products are available from three different sources namely GFZ (Geoforschungs Zentrum, Potsdam), CSR (Center for space research at the University of Texas, Austin) and JPL (Jet propulsion laboratory). For the present study, monthly CSR RL05.01M Mascon (Save, Bettadpur and Tapley, 2016 ) are used over a period from April 2002 to December 2016. Authors have selected this particular product for its high resolution $\left(0.5^{0} \times 0.5^{0}\right)$ and quality control as compared to other GRACE products. The GRACE monthly TWS anomaly (TWS_A) represents total vertical water balance composed of soil moisture anomaly (SM_A), snow water equivalent anomaly (SWE_A), surface water/reservoir storage anomaly (SW_A), canopy water content anomaly (CW_A) groundwater anomaly (GW_A) as shown in equation 1

$$
\begin{aligned}
& \text { TWS_A }=\text { SM_A }+ \text { SWE_A }+ \text { SW_A }+ \text { CW_A }+ \text { GW_A } \\
& \text { GW_A }=\text { TWS_A }-\left(S M \_A+S W E \_A+S W \_A+C W \_A\right)
\end{aligned}
$$

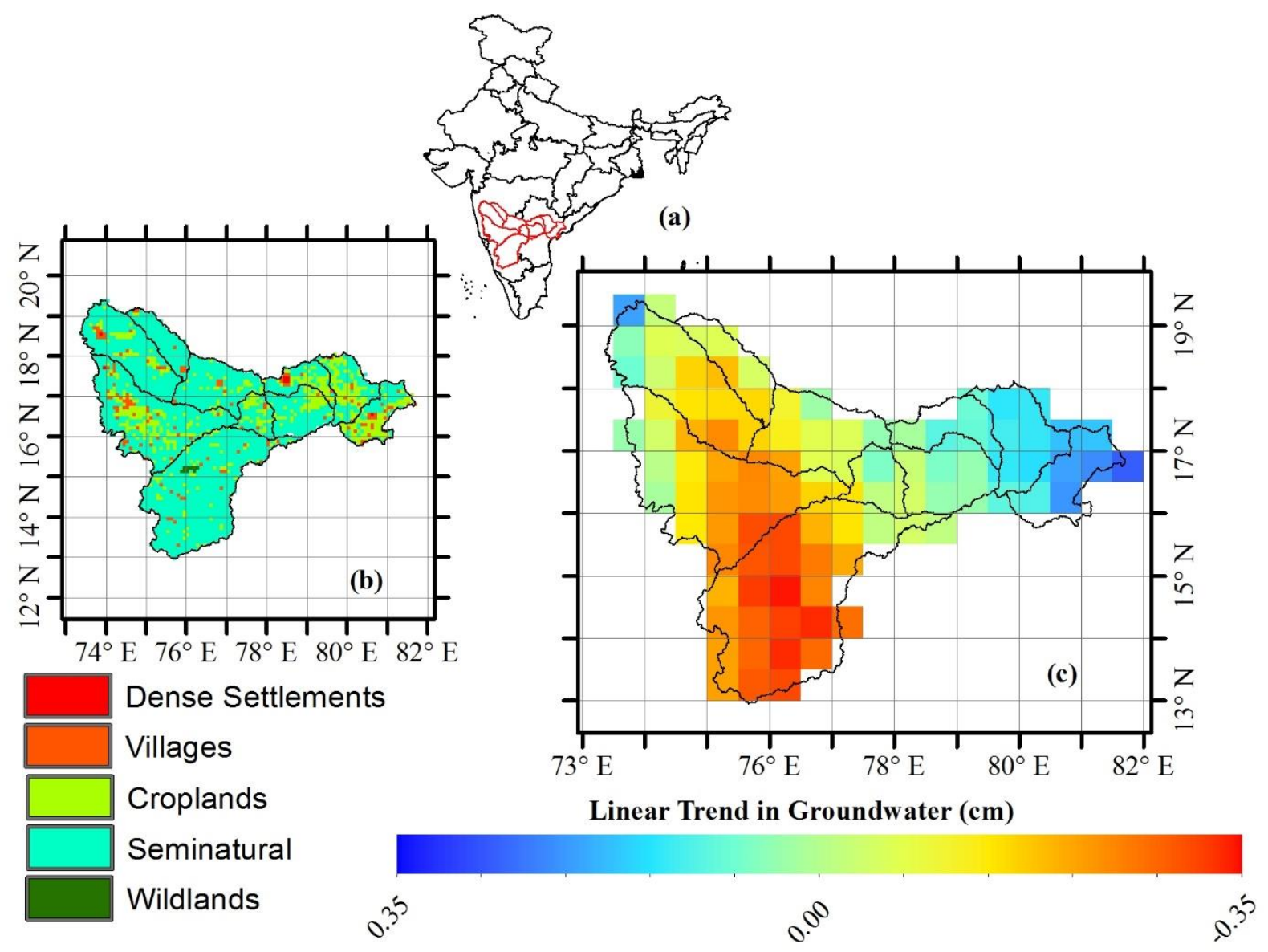

Figure 1. (a) Red lines indicate location of Krishna basin, (b) Anthropogenic Biome (For 2000, Source: Ellis et al., 2013), (c) Linear trend in groundwater derived from GRACE mascon 
Groundwater storage anomaly is estimated using equation 2 . The supporting files to compute groundwater are obtained from NASA Global Land Data Assimilation System (GLDAS; Rodell et al., 2004) Noah (Chen et al., 1996; Koren et al., 1999) model.

\subsection{IMD Precipitation Data}

The present study evaluated the impact of precipitation on groundwater using the latest version of daily gridded rainfall dataset (IMD4) from India Meteorological Department (IMD). Which has a spatial extent of $6.5^{\circ} \mathrm{N}$ to $66.5^{\circ} \mathrm{N}$ latitude and $66.5^{0}$ $\mathrm{E}$ to $100^{\circ} \mathrm{E}$ at a spatial resolution of $0.25^{0} \times 0.25^{0}$. The dataset is available for 115 years from 1901 to 2015 . It consists of observation from 6995 rain gauge stations, which is the highest number of stations used till date for the IMD products (Rajeevan et al., 2006; Pai et al., 2014). For this study, data is evaluated for a period from 2002 to 2015 .

\subsection{MODIS ET}

In order to study the impact of evapotranspiration (ET) on groundwater or vice versa, Moderate Resolution Imaging Spectroradiometer (MODIS) ET product is used. The MOD16A2 Version 6 data is globally available as an 8-day composite product with a spatial resolution of 500 meters (Running, Mu and Zhao, 2017). This product relies on the Penman-Monteith equation to compute ET from MODIS vegetation property, albedo, and landcover along with meteorological reanalysis data. The gridded MODIS products are averaged to the resolution of GRACE grid for the analysis of results.

Datasets used in the present study are summarized in Table 1.

Table 1. Summary of datasets used in the present study

\begin{tabular}{|c|c|c|c|}
\hline $\begin{array}{c}\text { Sr. } \\
\mathrm{N}\end{array}$ & Data & $\begin{array}{c}\text { Spatial } \\
\text { Resolution }\end{array}$ & Time period \\
\hline 1 & $\begin{array}{c}\text { CSR GRACE } \\
\text { mascon }\end{array}$ & $0.5^{0} \times 0.5^{0}$ & $\begin{array}{c}\text { April }-2002 \text { to } \\
\text { December }-2016\end{array}$ \\
\hline 2 & IMD4 & $0.25^{0} \times 0.25^{0}$ & 2002 to 2015 \\
\hline 3. & $\begin{array}{c}\text { MODIS ET } \\
\text { (MOD16A2) }\end{array}$ & $\sim 0.005^{0} \mathrm{x}$ & 2002 to 2016 \\
& \multicolumn{2}{c}{$005^{0}$} & \\
\hline
\end{tabular}

\section{METHODOLOGY}

The key objective of the present study is to evaluate the variability of groundwater in the Krishna Basin using GRACE observations. Towards this goal, the groundwater anomaly (GW_A) is separated from the total water storage anomaly (TWS_A) using equation 2. For this, the soil moisture in the unsaturated zone $(2 \mathrm{~m})$, canopy water content and snow water equivalent are obtained from 3 hourly GLDAS Noah model $\left(0.25^{0} \times 0.25^{0}\right)$. In order to compute the anomaly these datasets are converted to a monthly scale, the mean of monthly Noah

TWS (2002 - 2016) is subtracted from monthly datasets to obtain TWS anomaly contribution from the surface component. In the second stage of analysis a pixel-wise linear trend analysis is performed on the groundwater anomaly (GW_A) estimates. Further, to evaluate the variability of precipitation over the basin an entropy-based seasonality index is applied to the IMD precipitation over the basin (Feng et al., 2013; Sahany et al., 2018).

\subsection{Entropy based analysis}

To evaluate the variability of precipitation over the Krishna basin, an entropy based analysis adopted as proposed by Feng et al., 2013. For this analysis, long-term monthly mean rainfall accumulation $\left(\mathrm{r}_{\mathrm{m}}\right)$ are computed from daily IMD data for a period from 2002 to 2015 . Further the monthly rainfall probability distribution $\left(\overline{p_{m}}\right)$ is obtained by dividing $\mathrm{r}_{\mathrm{m}}$ with mean annual rainfall accumulation $(\bar{R})$. The relative entropy $(\bar{D})$ provides the information about the concentration of rainfall during a year from the departure of the monthly rainfall probability distribution $\left(\overline{p_{m}}\right)$ with respect to a uniform distribution $\left(q_{m}=1 / 12\right)$ as shown in equation (3)

$$
\bar{D}=\sum_{m=1}^{12} \overline{p_{m}} \log _{2} \frac{\overline{p_{m}}}{q_{m}}
$$

Seasonality index $(\bar{S})$ provides information about the distribution of rainfall during a year. For regions with uniformly distributed rainfall throughout the year seasonality index will be zero, while for regions receiving rainfall for only one month it attains a maximum value. The index is computed as a product of relative entropy and spatially normalized rainfall as shown in equation (4)

$$
\bar{S}=\bar{D} *\left(\frac{\bar{R}}{\overline{R_{\max }}}\right)
$$

Where, $\overline{R_{\max }}$ is the spatial maximum annual accumulated rainfall.

\subsection{The timing of peak and duration of rainy season}

The present study further evaluates the variation in timing of peak rainfall and duration of wet season. The yearly timing of peak $\left(C_{y}\right)$ is computed using equation (5)

$$
C_{y}=\frac{1}{R_{y}} \sum_{d=1}^{365} d r_{y, d}
$$

Where $R_{y}=$ the annual accumulated rainfall,

$d=$ the day of the year $(y)$,

$r_{y, d}=$ the daily rainfall

The duration of wet season for each year $\left(Z_{y}\right)$ is computed using equation (6)

$$
Z_{y}=\sqrt{\frac{1}{R_{y}} \sum_{d=1}^{365}\left|d-C_{y}\right|^{2}} r_{y, d}
$$

It is to be noted that for the entropy analysis in section 3.1, monthly $(m)$ accumulated precipitation data is used whereas in section 3.2 daily $(d)$ rainfall datasets are used. 


\section{RESULTS AND DISCUSSIONS}

\subsection{Trend Analysis of groundwater}

Figure 1(c) depicts the linear trend in groundwater anomaly derived from GRACE. The result indicates that majority of the basin has a negative trend in groundwater except for few regions in the northwest and the eastern region. Fig 1(b) represents the anthropogenic biomes over the basin (Ellis et al., 2013). It is observed that the majority of the region is covered in semi-natural and cropland area. The maximum rate of decline in groundwater is observed in the southern region at the rate of $0.34 \mathrm{~cm} /$ year This can be attributed to a combined effect of anthropogenic activities and rainfall variability.
In order to evaluate the variation in the rainfall an entropy based analysis is performed.

\subsection{Climatology of precipitation}

Figure 2 depicts spatial patterns of mean annual relative entropy, seasonality index, time for peak and duration of the wet season. Relative entropy (Figure 2a) is high over the Western Ghats region and lowest over the southern region. The high concentration of entropy indicates sharp seasonality of rainfall. Which can be justified with the fact that the Western Ghats in Maharashtra region receives rain during June, July, August, and September (JJAS). Further, the results indicate low entropy in southern and eastern regions.

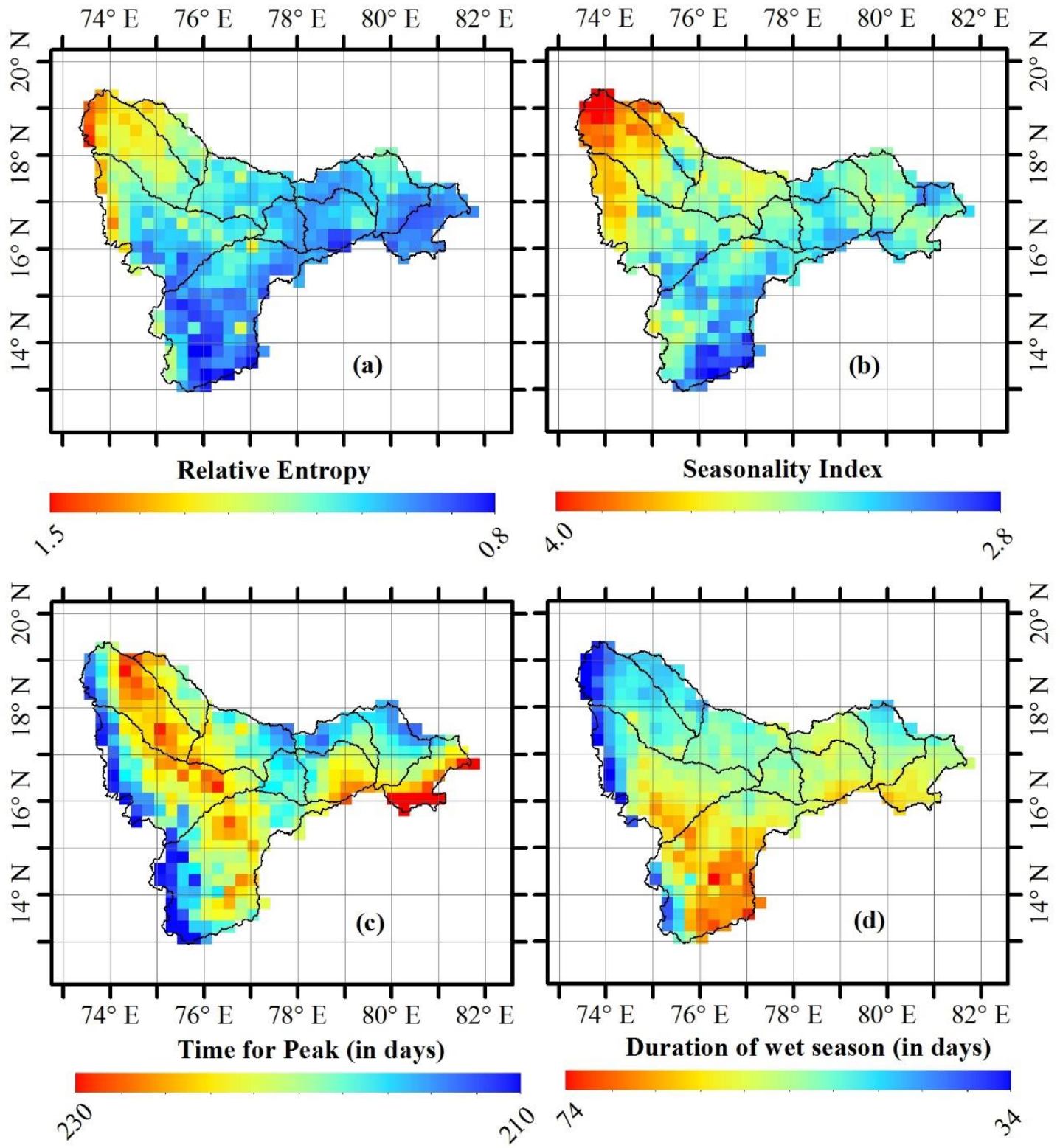

Figure 2. Represents spatial patterns of yearly mean for a period from 2002 to 2015 of (a) Relative entropy, (b) Seasonality Index, (c) Time for peak monsoon (in days), (d) Duration of wet season (in days) 
Which is owing to a longer monsoon over the region from the southwestern monsoon and northeastern monsoon. The seasonality index (Figure 2b) shows a similar spatial pattern with high seasonality over the Western Ghats region and low index over southern regions. India's rainfall climatology attains peak during Jul-August over the majority of states except for the southeastern peninsula which receives peak rainfall from September to November (Nair and Indu, 2017). Figure 2c indicates a similar result with western parts having a lower time to attain peak while the eastern and central portion of the basin attains peak after a lag of approximately 1 to 2 months. Similarly, the southeastern region of the basin experiences a longer monsoon season as compared to the western portion of the basin (Figure 2d)

\subsection{Trend in precipitation seasonality}

Figure 3 represents the spatial pattern of a linear trend in relative entropy, seasonality index, time for peak and duration of the wet season. The Western Ghats region and the northeastern coast of the basin indicate a positive trend in relative entropy and a negative trend in the southern region (Figure 3a). This indicates that the annual rainfall is more concentrated to a particular season over the positive trend regions while it is more spread in regions showing a negative trend. These results are consistent with the trend observed in seasonality index values (Figure 3b). The time for peak shows a negative trend (Figure 3c) over regions showing a negative trend in groundwater (Figure 1c).

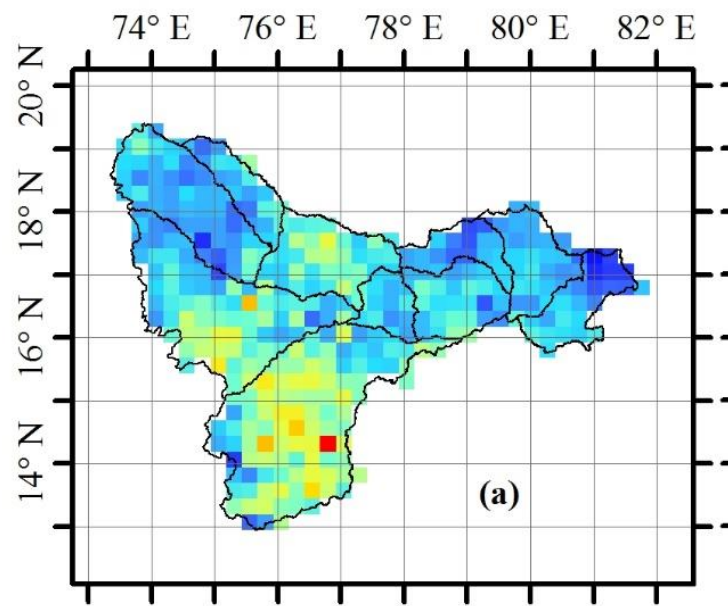

Linear Trend in Relative Entropy
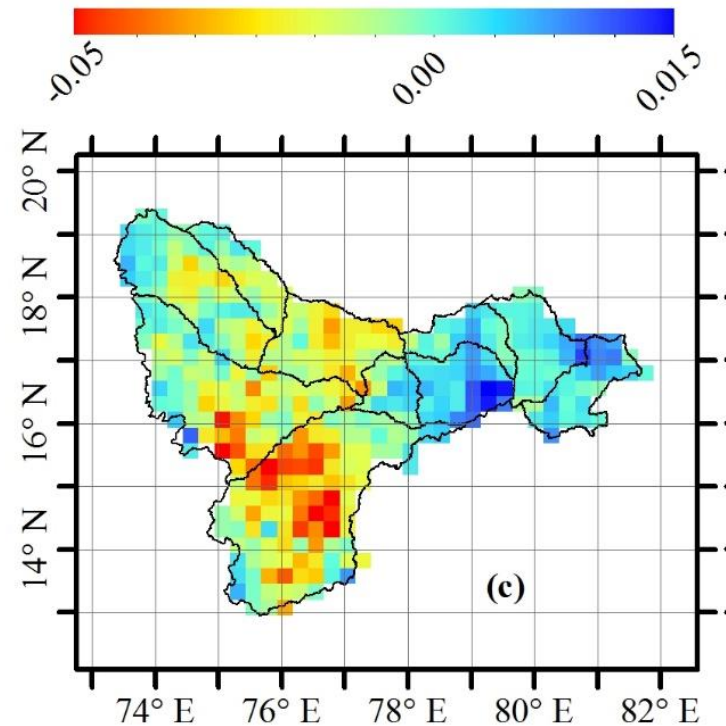

Linear trend in time for Peak

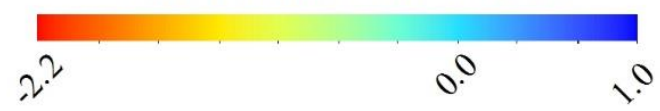

10

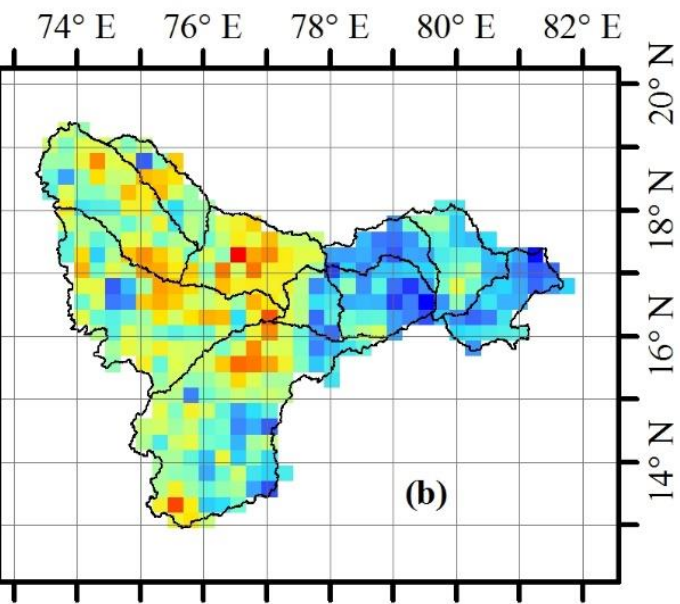

Linear Trend in Seasonality Index

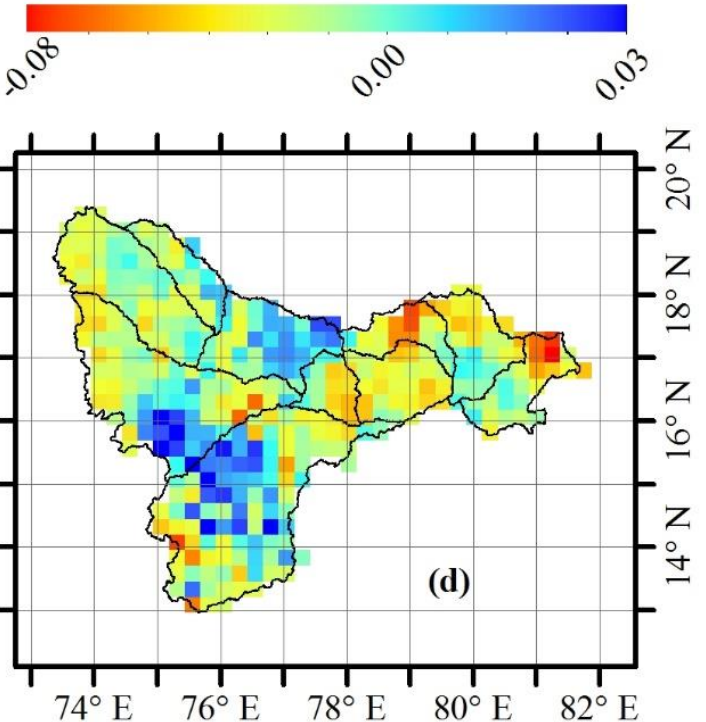

Linear trend in duration of wet season

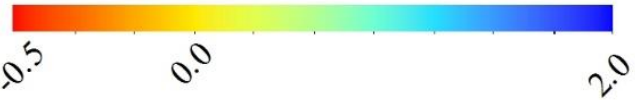

Figure 3. Represents spatial patterns of linear trend for a period from 2002 to 2015 for (a) Relative entropy, (b) Seasonality Index, (c) Time for peak monsoon (days), (d) Duration of wet season (in days) 
Similarly, the duration of the wet season follows a negative trend over the majority of the region except for the central portion (Figure 1d). Which indicates a slight decline in the monsoon season over the basin. This affects the groundwater recharge over the region as the only source of recharge is from precipitation and surface water unlike north Indian basins having recharge from glaciers.

\subsection{Groundwater link to precipitation and} evapotranspiration

This study further explores the dependence of yearly groundwater anomaly on evapotranspiration and precipitation seasonality. Figure 4a shows the correlation between yearly relative entropy with GRACE groundwater anomaly, it can be observed that groundwater shows a complex dependence on precipitation entropy with low and high correlation coefficients (CC) throughout the basin. However, the portion of the basin from $77^{\circ} \mathrm{E}$ to $79^{\circ} \mathrm{E}$ shows a high correlation between precipitation entropy and groundwater. Which indicates that a high concentration of precipitation leads to high groundwater anomaly in the region. Similar, results can be observed in seasonality index (Figure 4b).
From this result, it can be inferred that the sharp increase in seasonality increases the groundwater anomaly. Figure $4 \mathrm{c}$ indicates that majority of the basin shows a high correlation between time of peak and groundwater anomaly. From this result, it can be inferred that increase in time of peak (i.e delay in rainfall peak) results in an increase in groundwater anomaly. Figure $4 d$ shows that the majority of the basin has a negative correlation between evapotranspiration (ET) and groundwater anomaly. Which shows that high evapotranspiration of surface water increases the percolation and reduces the groundwater anomaly. However, the southern region of the basin shows a positive correlation. Where the increase in ET increases groundwater anomaly which is in accordance to the Figure 1c. Further, Figure $4 \mathrm{e}$ indicate that groundwater anomaly has a negative CC with duration of the monsoon season. Hence, it can be concluded that a decrease in the duration of the wet season increases the anomaly in groundwater.

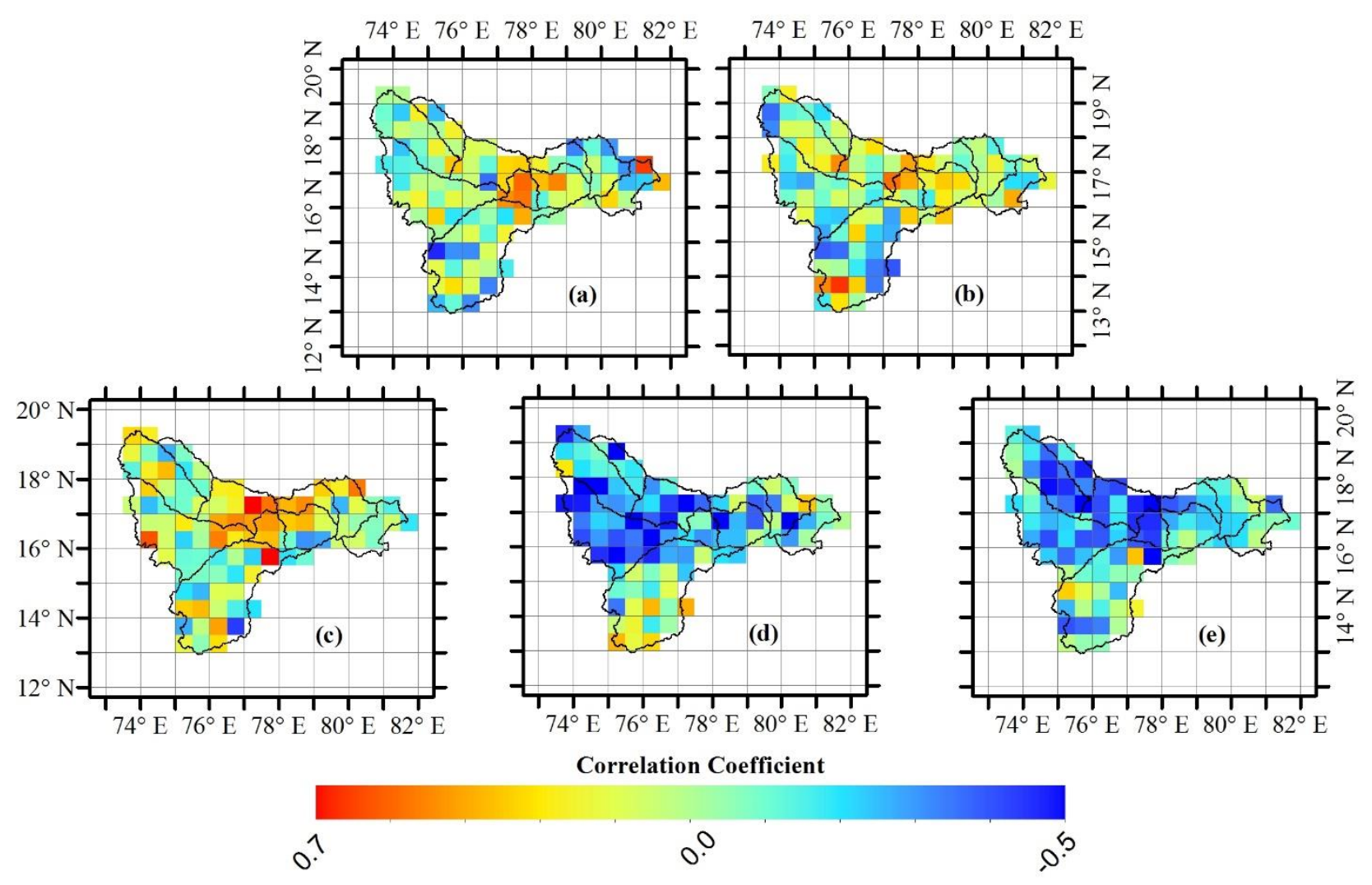

Figure 4. Depicts spatial pattern of correlation coefficient between groundwater and (a) Relative entropy, (b) Seasonality Index, (c) Time for peak monsoon, (d) Evapotranspiration, (e) Duration of wet season 


\section{SUMMARY}

Previous studies on evaluation of groundwater highlight the strong negative trend in the North-western states neglecting the southern regions (Rodell et al., 2009; Tiwari et al., 2009; Chen et al., 2014, Bhanja et al., 2016). The present study shows that the Krishna Basin in South India is also subjected to a strong negative trend in groundwater. It further studies the changes in rainfall seasonality using an entropy-based approach.

The results from this study indicate that the groundwater storage in the Krishna basin (Karnataka region) is reducing at a rate of $0.34 \mathrm{~cm}$ per year. Precipitation over the Krishna basin is subjected to a negative decline in seasonality over the Western Ghats region. The high concentration of rainfall seasonality in conjunction with the reduction in the wet season reduces the groundwater recharge time. The study further shows a strong link between evapotranspiration (ET) and groundwater anomaly. This study provides an insight into the groundwater condition over the Krishna basin. It will help the government bodies to implement robust strategies for a sustainable futuristic groundwater storage.

\section{ACKNOWLEDGEMENT}

The authors thankfully acknowledge India Meteorological Department for precipitation data. CSR RL 05 mascon data are available at the Center for Space Research at the University of Texas at Austin. GLDAS output is available at the Goddard Earth Sciences Data and Information Services Center, NASA.

\section{REFERENCES}

Banerjee, C., Kumar, D. N., 2018. Assessment of surface water storage trends for increasing groundwater areas in India. Journal of Hydrology. 5p.780-788, doi.org/10.1016/j.jhydrol.2018.05.052

Becker, M., Llovel, W., Cazenave, A., Güntner, A., Crétaux, JF., 2010. Recent hydrological behavior of the East African great lakes region inferred from GRACE, satellite altimetry and rainfall observations. Comptes Rendus Geoscience, 342(3), pp.223-233. doi.org/ 10.1016/j.crte.2009.12.010

Chen, F., Mitchell, K., Schaake, J., Xue, Y., Pan, H.-L., Koren, V., Duan, Q.Y., Ek, M., Betts, A., 1996. Modeling of land surface evaporation by four schemes and comparison with FIFE observations. J. Geophys. Res. Atmos. 101, pp.7251-7268. doi.org/10.1029/95JD02165

Chen, J., Li, J., Zhang, Z., Ni, S., 2014. Long-term groundwater variations in Northwest India from satellite gravity measurements, Global and Planetary Change, 116, pp.130-138, doi.org/10.1016/j.gloplacha.2014.02.007

Ellis, E. C., Goldewijk, K. K., Siebert, S., Lightman, S., and Ramankutty, N., 2013. Anthropogenic biomes of the world, version 2, 1700. Palisades, NY : NASA socioeconomic Data and Applications Center (SEDAC). https://sedac.ciesin.columbia.edu/data/set/anthromesanthropogenic-biomes-world-v2-1700. (04 June 2018)

Entekhabi, D., Njoku, E.G., O’Neill, P.E., Kellogg, K.H., Crow, W.T., Edelstein, W.N., Entin, J.K., Goodman, S.D., Jackson, T.J., Johnson, J., Kimball, J., Piepmeier, J.R., Koster, R.D., Martin, N., McDonald, K.C., Moghaddam, M., Moran, S.,
Reichle, R., Shi, J.C., Spencer, M.W., Thurman, S.W., Tsang, L., Van Zyl, J., 2010. The soil moisture active passive (SMAP) mission. Proc. IEEE 98, pp.704-716. doi.org/10.1109/JPROC.2010.2043918

Feng, X., Porporato A., \& Iturbe, I. R., 2013. Changes in seasonality in the tropics . Nature Climate Change , 3 (9),pp. 811815 . doi.org/10.1038/NCLIMATE1907

Food and Agriculture Organization, 2012. Irrigation in Southern and Eastern Asia in Figures. FAO, Land and water division, Water Reports 37

Gaiser, P.W., St. Germain, K.M., Twarog, E.M., Poe, G.A., Purdy, W., Richardson, D., Grossman, W., Jones, W.L., Spencer, D., Golba, G., Cleveland, J., Choy, L., Bevilacqua, R.M., Chang, P.S., 2004. The windSat spaceborne polarimetric microwave radiometer: Sensor description and early orbit performance. IEEE Trans. Geosci. Remote Sens. 42, pp.2347-2361. doi.org 10.1109/TGRS.2004.836867

Hassan A, Jin S, 2016. Water storage changes and balances in Africa observed by GRACE and hydrological models, Geodesy and Geodynamics, Vol 7-1, pp.39-49, doi.org/10.1016/j.geog.2016.03.002

Indian Water Resources Society (IWRS), 1997. River basin management: issues and options. Theme paper for water resources day, New Delhi, India

India-WRIS, Water resources information system of India, https://www.india-wris.nrsc.gov.in/wrpinfo/index.php?title= Krishna, (29 July 2018).

Kerr, Y.H., Waldteufel, P., Wigneron, J.-P., Delwart, S., Cabot, F., Boutin, J., Escorihuela, M.-J., Font, J., Reul, N., Gruhier, C., Juglea, S.E., Drinkwater, M.R., Hahne, A., Martín-Neira, M., Mecklenburg, S., 2010. The SMOS Mission: New Tool for Monitoring Key Elements of the Global Water Cycle. Proc. IEEE 98, 666-687. doi.org/10.1109/JPROC.2010.2043032

Koren, V., Schaake, J., Mitchell, K., Duan, Q.-Y., Chen, F., Baker, J.M., 1999. A parameterization of snowpack and frozen ground intended for NCEP weather and climate models. $J$. Geophys. Res. Atmos. 104, 19569-19585. doi.org/10.1029/1999JD900232

Nair, A. S., Indu, J., 2018. A Coupled Land Surface and Radiative Transfer Models Based on Relief Correction for a Reliable Land Data Assimilation Over Mountainous Terrain, IEEE Geoscience and Remote Sensing Letters (Accepted for inclusion in a future issue) doi.org/10.1109/LGRS.2018.2854908

Nair, A.S., Indu, J., 2017. Performance Assessment of MultiSource Weighted-Ensemble Precipitation (MSWEP) Product over India. Climate 5, pp.1-20. doi.org 10.3390/cli5010002

Nair, A.S., Indu, J., 2016. Enhancing Noah Land Surface Model Prediction Skill over Indian Subcontinent by Assimilating SMOPS Blended Soil Moisture. Remote Sensing.,8,p.976, https://doi.org/10.3390/rs8120976

Pai, D. S., Sridhar, L., Rajeevan, M., Sreejith, O. P., Satbhai, N S., and Mukhopadyay, B., 2014. Development of a new high spatial resolution $\left(0.25^{0} \times 0.25^{0}\right)$ long period $(1901-2010)$ daily 
gridded rainfall data set over India and its comparison with existing data sets over the region, Mausam, 65-1, pp.1-18

Rajeevan, M., Bhate, J., Kale, J. D., and lal, B., 2006. High resolution daily gridded rainfall data for the Indian region: Analysis of break and active monsoon spells, Current Science, 91(3),pp.296-306

Rodell, M., Houser, P.R., Jambor, U., Gottschalck, J., Mitchell, K., Meng, C.-J., Arsenault, K., Cosgrove, B., Radakovich, J., Bosilovich, M., Entin, J.K., Walker, J.P., Lohmann, D., Toll, D., Rodell, M., 2003. The Global Land Data Assimilation System. Bull. Am. Meteorol. Soc, 85(3),.pp.381-394. doi.org/10.1175/BAMS-85-3-381

Rodell, M., Velicogna, I., and Famiglietti, J. S., 2009. Satellitebased estimates of groundwater depletion in India, Nature Letters, 460, pp.999-1003, doi.org/10.1038/nature08238

Running, S., Mu, Q., Zhao, M., 2017. MOD16A2 MODIS/Terra Net Evapotranspiration 8-Day L4 Global 500m SIN Grid V006 [Evapotranpiration]. NASA EOSDIS Land Processes DAAC. doi.org/10.5067/MODIS/MOD16A2.006.

Sahany, S., Mishra, S. K., Pathak, R., \& Rajagopalan, B., 2018. Spatiotemporal variability of seasonality of rainfall over India. Geophysical Research Letters, 45. doi.org/10.1029/2018GL077932

Save, H., Bettadpur. S., Tapley, B. D., 2016, High-resolution CSR GRACE RL05 mascons, Journal of Geophysical Research: Solid Earth, pp.121-10, doi.org/10.1002/2016JB013007

Tiwari, V. M., Wahr, J., and Swenson, S., 2009. Dwindling groundwater resources in northern India, from satellite gravity observations, Geophysical Research Letters, 36, L18401, doi.org/10.1029/2009GL039401

Wagner, W., Hahn, S., Kidd, R., Melzer, T., Bartalis, Z., Hasenauer, S., Figa-Saldaña, J., De Rosnay, P., Jann, A., Schneider, S., Komma, J., Kubu, G., Brugger, K., Aubrecht, C., Züger, J., Gangkofner, U., Kienberger, S., Brocca, L., Wang, Y., Blöschl, G., Eitzinger, J., Steinnocher, K., Zeil, P., Rubel, F., 2013. The ASCAT soil moisture product: A review of its specifications, validation results, and emerging applications. Meteorol. Zeitschrift 22, pp.5-33. doi.org/10.1127/09412948/2013/0399 